\title{
Consumer Behavior towards Green Building: A Study in Abu Dhabi
}

\author{
Emadeldin Abuamer ${ }^{1} \&$ Mehraz Boolaky ${ }^{2}$ \\ ${ }^{1}$ University of Liverpool- Laureate, UK; Founder and the General Manager of Barracuda E\&M, Abu-Dhabi, UAE \\ ${ }^{2}$ Honorary Lecturer and Dissertation Adviser, University of Liverpool/Laureate, UK; Asia Pacific Institute of \\ Management, New Delhi, India \\ Correspondence: Mehraz Boolaky, Honorary Lecturer and Dissertation Adviser, University of Liverpool/Laureate, \\ UK; Professor of Marketing, Asia Pacific Institute of Management, New Delhi, India. E-mail: \\ mehraz.boolaky@online.liverpool.ac.uk
}

Received: March 31, 2015

doi:10.5430/ijba.v6n3p72
Accepted: April 18, 2015

Online Published: May 7, 2015

URL: http://dx.doi.org/10.5430/ijba.v6n3p72

The study was carried out as part of Master studies of the lead author at the University of Liverpool/Laureate under the supervision of the second author (Dr Mehraz Boolaky).

\begin{abstract}
Green energy is a concept that has developed dramatically in recent years, for both professionals and regular consumers. One of the most important applications of green energy is 'Green Buildings'. This paper discusses Green Buildings from the perspective of the local consumers of Abu Dhabi city. Various elements of consumer preferences towards green buildings are evaluated in order to gauge their marketability in Abu Dhabi real estate market and the level of competition in the area. One of the research main themes is to evaluate existing Green Building support and recommending future anticipated support to boost the growth of the green construction industry. Primary data was collected through face to face interviews using a convenience sample of sixty respondents. This study has shown that Green Buildings are marketable products with their own marketable features; marketing tools sometimes are different from the tools used to market conventional buildings. Taken together, the study recommends stakeholders to invest more in green construction that will ultimately lead to solid growth in the industry of Green Buildings.
\end{abstract}

Keywords: green energy, green building, consumer behaviour, environmental rules and regulation, LEED (Leadership in Energy and Environment Design)

\section{Background}

Green energy is a concept that has developed dramatically in recent years, for both professionals and regular consumers. One of the most important applications of green energy is 'Green Buildings'. The fact that commercial buildings are considered one of the major elements in the environmental equation creates new horizon for Green Buildings. According to Rehm and Ade (2013, p.198), buildings in Europe consumes 16\% of potable water, 50\% of raw material and $40 \%$ of solid landfill waste. Therefore, focusing efforts on turning conventional buildings into 'Green Buildings' and constructing new buildings on green principals are the most viable approach to respond to environmental issues and sustainability concerns. In fact, Liu and Wang (2013) assert that green building is now an 'inevitable trend' of construction industry because of its propensity to furnish low power consumption, high environmental protection and in harmony with nature etc. Accordingly, Green Buildings are the highest green segment in terms of capital value. About \$229 billion investment is needed to make 129 million U.S. homes more energy efficient and could save $\$ 395$ billion where commercial buildings would require $\$ 125$ billion to save $\$ 290$ billion (Snyder, Tate and Winters, 2011, p.13). The magnitude of these huge numbers is pivotal in convincing all stakeholders including firms and governments to prioritize Green Buildings over other green segments. The city of Abu-Dhabi is no exception when it comes to drawing the new face of the construction industry. Early 2009, the local authority launched a green building regulating body, similar to US LEED (Leadership in Energy and Environment Design), Called Estidama. The new body is concerned with imposing proper green construction codes which are practical and environmental friendly at the same time. The city is conveying a very important message to all main players in the real estate industry, especially commercial building sector; that the mere financial return on investment is no longer acceptable for commercial building constructions. The city is introducing two additional dimensions 
when evaluating commercial buildings. The first one is the impact of the newly constructed buildings on the environment and the second dimension is adopting much more efficient energy scheme than the conventional one used in the past. The city environmental concerns have come from numerous academic and scientific sources. In this matter, Sharples and Radhi (2013) explain that this region has three main issues;

1- The region has reached an alarming level of pollution

2- The importance of introducing modern green framework

3- When it comes to construction, the mindset of decision makers has to place greater emphasis on environment and green energy

From another point of view, Green construction does not succeed or grow by merely introducing obligatory rules and regulations. Proliferating green construction will be viable only when the property is received positively by the end-user and meets his/her expectation. Property customers need to change their purchasing habits and start shopping for green properties in order to make significant difference in the real estate industry. Therefore, Green apartments and commercial properties have to appeal to consumers. To achieve significant shift in the property purchasing habit, sellers have to adopt compatible marketing means and management. Marketing Green Buildings will not succeed if the product is not in touch with consumer preferences and concerns. Brohmann (2013) conducted a literature review on consumer behaviour towards energy conservation in residential buildings, assuming that some tenants might be uninterested in energy-saving investments or those for whom energy costs are unimportant. The review reveals that consumers accept to pay more for green electricity if everyone else is 'involved and committed' (Brohmann 2013, p.30).

\subsection{Aims of the Study}

From the broader perspective, this study is designed to offer practical green solutions for today's construction problems. Green construction is not effective if it is not spread and flourished in the local property market. Since, consumers are the purchasing power and the real driving wheel of the industry (Moisander, Markkula and Erarnta, 2010, p. 75), evaluating consumer receptive mood is significant in advancing this new field. The main aim of this study is to investigate building features which appeal to real estate consumers. Second, the study looks into possible marketing tools which enhance the flourishing of Green Buildings. Finally, it aims to look into consumer behavior and reactions toward Green Building suggested solutions; risks and challenges of this newly born industry.

\subsection{Research Questions}

The study is mainly focused on providing insightful answers to the following research questions;

- How to position the product of Green Building in the property market with a view to identify the most important characteristic that meet consumer's preferences?

- What are the features that appeal to green real estate potential buyers?

- What are the marketing tools to approach consumers?

Closing the gap between Green Building properties and conventional commercial buildings requires innovative marketing arguments and effective communication approach to the topic. The strategy is based on identifying the industry strengths, and been able to capitalize on the contributing factors; at the same time, weaknesses should be addressed to alleviate their negative effects on the consumer's mind.

\section{Literature Review on Green Building Implementation}

\subsection{Green Building as a Concept in Various Countries}

Green Building construction is a new concept. On the international level, World Green Building Council (WGBC) was just established in 1999. This council and regional councils are mainly focused on promoting buildings that are environmentally responsible, economically viable, and healthier in its surroundings. Testing consumer behavior findings of Green Buildings in the city of Abu-Dhabi is not a common practice. Nevertheless, Studies and surveys about consumer behavior towards Green Buildings were conducted in other parts of the world. The following findings were taken from North America, Europe, China, South America, and South Africa.

Schnizter (2010, p.36) explains that $98 \%$ of respondents in favor of green communities but only $25 \%$ act accordingly. The author adds that both Canadians and Americans have increasing concerns about the credibility of green statements advertised by commercial firms. The public concern with the environmental issues was tested in the study of Brasington and Hite (2005). They found that the price of a property depreciates only $1 \%$ when it is located $10 \%$ closer to environmental hazards. When the house is more than a mile away from hazard area, $6 \%$ loss in the house 
value is detected when moving a mile and a half closer (Brasington and Hite, 2005, p.73). In the cold Canadian areas, residents are willing to pay more in a prioritized order for the following construction features; energy savings, natural light, thicker insulation, anti-allergic material, air tightness, outside noise proof, inside noise proof, forced ventilations, and artificial light (Septic, Kozar and Cohen, 2005, p.23).

Jim and Chen (2007, p.420) look into consumer behavior toward commercial flat appealing features in Guangzhou China; the results of the study provide comprehensive overview about the importance of relevant construction features to city residents. The selected features are transaction price, security concerns, property management and proximity of work, shopping areas, public transportation to the property.

In South Africa, Thatcher and Milner (2012) investigate the effect of Green Buildings on the physical and psychological wellbeing of humans. The study confirms that some elements of Green Buildings such as indoor air quality, natural daylight, and improved ventilations are positively correlated with human wellbeing. Nevertheless, the study does not find any significant difference between the outputs of citizens when living in star accredited South Africa Green Buildings comparing to conventional commercial buildings.

\subsection{Costs of Green Buildings}

Rehm and Ade (2013) discuss the public impression about the cost of green properties in the European Union; the study confirms other literature findings which state that property cost is not evaluated in simple dollars and cents. Introducing the variances of operation costs, anticipated breakdowns and improved public health bill makes the overall cost harder to evaluate; therefore, the public impression becomes more significant in buying green real estate properties. The study explains that $86 \%$ of the public think that Green Buildings are more expensive than conventional commercial buildings, $13 \%$ think they cost the same, and only $1 \%$ think they cost less.

\section{Green Building - a few countries experience}

Levin (2013) concentrates his scope of study on the lower cost segment of green constructions in Brazil. The study supports the notion which directs low cost construction sector toward greener building practices. It is difficult to overcome the challenge of maintaining public transparency toward the newly developed construction model; a Green Building is not well defined in its specifications and applications comparing to conventional buildings. Nevertheless, expected benefits such as sustainability, healthier environment, and improved transportation means are essential elements in alleviating the harsh conditions of Brazilian poor communities.

Consumer behavior studies towards green building construction are influenced by three main factors. The first one is the location of the study; depending on survey's location, the preferences of the customer change. Each location has its own circumstances where residents who live in cold areas are interested in preserving heat and residents who live in hot areas do the opposite. Similarly, property customers are disturbed by desert dust and sand storms in this region. Such phenomenon does not exist in Northern parts of North America like Canada and north east regions of the USA. The public does not have a sense of this problem; on the contrary, they are concerned more about wet land solutions. Time is another factor in analyzing consumer behavior studies. The reason is that the public awareness change every year; Jim and Chen (2007, p.428) argue that the Chinese society develops until the green knowledge gap between them and the western world closes. The advancement in the technology and the level of literacy influence consumer preferences; Brasington and Hite (2005, p.57) argue that people with higher income, higher education and more children demand more environmental quality. The third factor is the priority of the local environmental issue; for example, some areas are directly influenced by smog where others are influenced directly with land draughts. Even environment and sustainability elements change according to the local circumstances. Consequently, solutions and building practices will change accordingly and better marketing strategies and more creative approaches are likely to be a future necessity.

\subsection{Green Building Three Dimensional Objectives}

If Green Buildings are compared with conventional buildings based on economics, conventional buildings will always prevail as the better choice for consumers. In recent years, there has been an increasing amount of literature on construction dimensions other than economics to highlight the advantages of Green Buildings. Starting from the definition of Green Buildings, one can sense the emphasis on new elements of construction such as environment, sustainability, healthy lifestyle and so on. Shiha, Gupta, and Kutnar (2012, p. 46) state, "Green building is the practice of creating structures and using processes that are environmentally responsible and resource-efficient throughout a building lifecycle from siting to design, construction, operation, maintenance, renovation, and deconstruction." The authors maintain the notion that Green Building definition keeps evolving and changing as the technology keeps on innovating new ways of living green. It is insightful to think of Green Buildings in terms of 
green sustainability. Shiha, Gupta, and Kutnar (2012, p.46) suggest green environmental sustainability as closed material loop, full integration into landscape after the structure is completed, and based on ecological principal; they point that sustainable development and Green Buildings are often used interchangeable. Schnitzer (2010) argues that green apartments are competing against older conventional ones which are based on well-defined and well-proven conventional building technologies. In addition, if the marketing agent aims to overcome other features such spaciousness of older apartments, the marketing strategy of new Green Buildings has to overcome consumer skepticism and doubts about the newly developed green apartments. According to Pilcher (2013:10) about 80\% of consumers prefer green products while $17 \%$ percent actually purchase them. If features such as maintenance cost, service reliability and tenant comfort; some specific differentiating features are indoor air quality, natural light distribution, and fresh air circulation are included in marketing communications, the probability to go for green buildings is likely to be higher (Haddock-Fraser and Tourelle, 2010). It is also important to highlight the aspect of hazard sites. This particular narrow concept was studied by Brasington and Hite (2005); the authors used empirical model to prove the insensitive mood of the public to the proximity of hazard sites, specifically when it is located more than a mile and a half away.

\subsection{Driving Consumer Preferences towards Green Buildings}

No matter how often new environmental rules and regulations are imposed or changed, the progress of green construction will only succeed through consumer demand and strong purchase appeal. Miosander, Markkula, and Eraranta (2010, p.73) point out that the importance and leading role of the consumer demand. First, the authors highlight consumer governing role, and reconfirming the consumer's position as a powerful market force, particularly when new technologies are meant on providing better life style and standards to consumers through improved air quality indoors and outdoors, natural lighting, efficient energy, air tightness, water high consumption, and waste water treatment. Jim and Chen (2007) argue, under the same topic, that Chinese who live in Guangzhou place property price and security arrangement as top priority when purchasing a new flat where environment and social parameters came in third and fourth order. Despite the fact that proximity to work and shopping centers are slightly related to green building accreditation elements in the US Green Building Council, the Chinese public do not prioritize environment greatly when making personal investment decisions.

One of the main challenges associated with green technologies is the limited knowledge that the developers have about consumer preferences. Knowledge limitation contributes greatly in capping what the consumer is willing to pay for the green dimension of the property. In Canada, Septic, Kozar, and Cohen (2005, p.23) explain that 3,592 Canadian households keep change their selection approach toward property preferences according to time and circumstances. In fact, consumers are willing to pay for a number of features in the following order: efficient energy, natural light, better insulation, anti-allergic material, air tightness, outside noise proof, inside noise proof, and forced ventilation. These factors are not marketed necessarily as green elements. In fact, they were enhancement elements in the conventional property market when selling to higher class of real estate customers. The authors argue that conventional buildings continuous development contributed greatly in receiving the concept of environmentally friendly properties positively. Earlier, people were attracted to the concept of healthier homes; for this reason, Canadian households became willing to pay more for better environmental quality and healthier living elements.

Moisander, Markkula and Eraranta (2010, p.75) argue that there are four main marketing guidelines for any green product. In their analysis of green marketing, they found that the universal guidelines apply to green marketing just like any other product. The first principle is visibilities and visual representation that include visual images, objects and arrangements. For instance in green building marketing, posters and energy saving models are good examples. Second, Knowledge and expertise are important to green building marketing. Moisander, Markkula and Eraranta (2010, p. 75) highlight the fact that knowledge and expertise offered by governing bodies are essential to effective marketing strategy; it also includes surveys, studies and green researches. The third principle is "Techniques and practices of government;" it is important to mention that government help to drive the consumer demand that shapes the market. Therefore, successful innovations would lead customers to imagine unarticulated needs instead of following well known needs. The key is to initiate an update or modification that triggers certain needs to the consumer. The last marketing principle is identities and forms of identification; the authors developed the concept of creating a consumer desire from scratch. In the green sector, one can claim that the identification of being green or environmentalist would be an identification formation. The marketing strategy is based on appealing to the ethical side or the reputation side of the customer.

Akehurst, Afonso and Goncalves (2012, p. 972) explain that there are four essential green marketing elements any project has to possess. They are; customer satisfaction, product safety, social acceptability and product sustainability. 
According to the authors, the higher the literacy level of the public is, the higher the chances are for consumers to buy green products. Green marketing, at the end, has to be an integral part of the green management of the project. Yudelson (2007) argues that marketing is about persuasive communication. To be persuasive, supported facts and creative ideas are essential to convey the green concept.

Rehm and Ade (2013) explain that combating serious issues such as natural resource depletion and water shortages contributes greatly in advocating Green Building solutions. Scientific facts indicate that construction is a major pollution source; therefore, alleviating the negative effects of construction through green means makes huge difference in the collective effort to save the environment. Similar approach is suggested to combat serious social issues in Brazil (Levin, 2013, p. 36). In crowded and poor communities, tenants suffer from poor quality drinking water, poor ventilations, toxic building materials, and pest problems. Such issues have devastating long term effect on child development, and resident productivity; nevertheless, turning these communities into green will imply additional cost. If governments and local authorities weigh the long term benefits on these communities, funding green housings will appeal to policy makers. Levin (2013, p. 37) recognizes the myth that variables and uncertainties associated with green construction makes it harder to guarantee transparency when granting housing funds. In this respect, Gauthier and Wooldridge (2012) also opine that LEED plays an important role in adoption as it is more likely to occur among companies that are more oriented toward end-consumers and those strategically positioned as environmental leaders.

Snyder, Tate and Winters (2011, p.13) shed light on the human resource factor in the Green Building industry. It explains why Green Building industry is appealing to policy makers and government bodies. The authors argue that the green sector is a great magnate for certain white color worker class who wants to serve the environment in one way or another. This sector and similar industries employed 3.1 million people of age 44-70 in the past few years in the US. Those professionals usually have great experience in conventional building technologies. Innovation and creativity ought to drive people to join and contribute in advancing the Green Building sector.

\subsection{Theoretical Framework}

This research is based on evaluating consumer behavior toward Green Buildings through sensing consumer preferences rather than obligatory measures. Various elements appeal to consumers. One method used to evaluate literature findings is to compare the survey, conducted locally in the city of Abu Dhabi, with literature to sense the opinions of Abu Dhabi residents. The evaluation criteria used in this study have three main elements: economics, environment and energy. Green Building features as revealed from the literature are driven exclusively by consumers through attractive features (positive features), undesired features (negative features) and practical marketing tools. Positive features consist of indoor and outdoor air quality, energy saving, natural lighting, improved thermal insulation, anti-allergic material, air tightness and noise proof. Negative elements are green-washing, Green Building risks, Green Building challenges and the short history of the industry. Marketing tools collected from various literature reviews consist of LEED certification and rating, Green reputation, healthy life style, government incentives, lifting undesired subsidies and promoting public green reputation.

\section{Research Methodology}

The quantitative approach was used in this study as it offers concise and numerical results which are clearer and easier to comprehend by concerned parties and stakeholders (Easterby-Smith, Thorpe and Jackson, 2008, p.231).

The targeted participants were solely consumers who could be potential future buyers or tenants to any type of real estate property in the city of Abu Dhabi. Commonly, consumers with such interest range from 22 to 60 years of age. Since the study took place in the Middle East, residents were expected to be compliant with cultural norms; in this case, couples at this range of age are expected to be looking for a property or replacing an existing one. Since this study targets consumers in general, the survey was conducted in available public space. Some of these meeting places included Shopping centers, Indoor malls, international franchise coffee shops, Arabic coffee shops, entertainment centers, and health clubs.

Primary data was collected through interviews and pilot tested questionnaires. Questions are divided into two sections; screening and main body. The two screening questions are prerequisite to move to accept the sample as acceptable participant. The second question section is directly related to the objectives and aim of the study. All the questions are related to the four study aims. The first one is Green Building features that are currently appealing to consumers. The second aim is current marketing tools used in Green Buildings and anticipated consumer behavior. Green-washing phenomenon in the local market and anticipated influence on consumer behavior is the third aim. The last point is consumer impression about green building. 
According to Easterby-Smith, Thorpe and Jackson (2008, p.231), Interviewer administered questionnaires are preferred when accurate results are priority. The sample size was limited to sixty subjects; "it is almost always better to have a smaller dataset of accurate answers than a larger dataset riddled with errors" (Easterby-Smith, Thorpe and Jackson, 2008, p.231).

\section{Results and Discussions}

This section presents the results of survey conducted on Abu Dhabi residents where volunteers were selected from different age categories.

\subsection{Appealing Features to Consumer}

The first set of questions is focused on evaluating consumer preferences toward their future property; the total number of questions is six, ranging from Q1 to Q6.

Figure 1 represents the answers of all of the sixty participants who were interviewed. The first question for the participant what attracts him/her to Green Buildings; the answers of are illustrated in Figure 1.

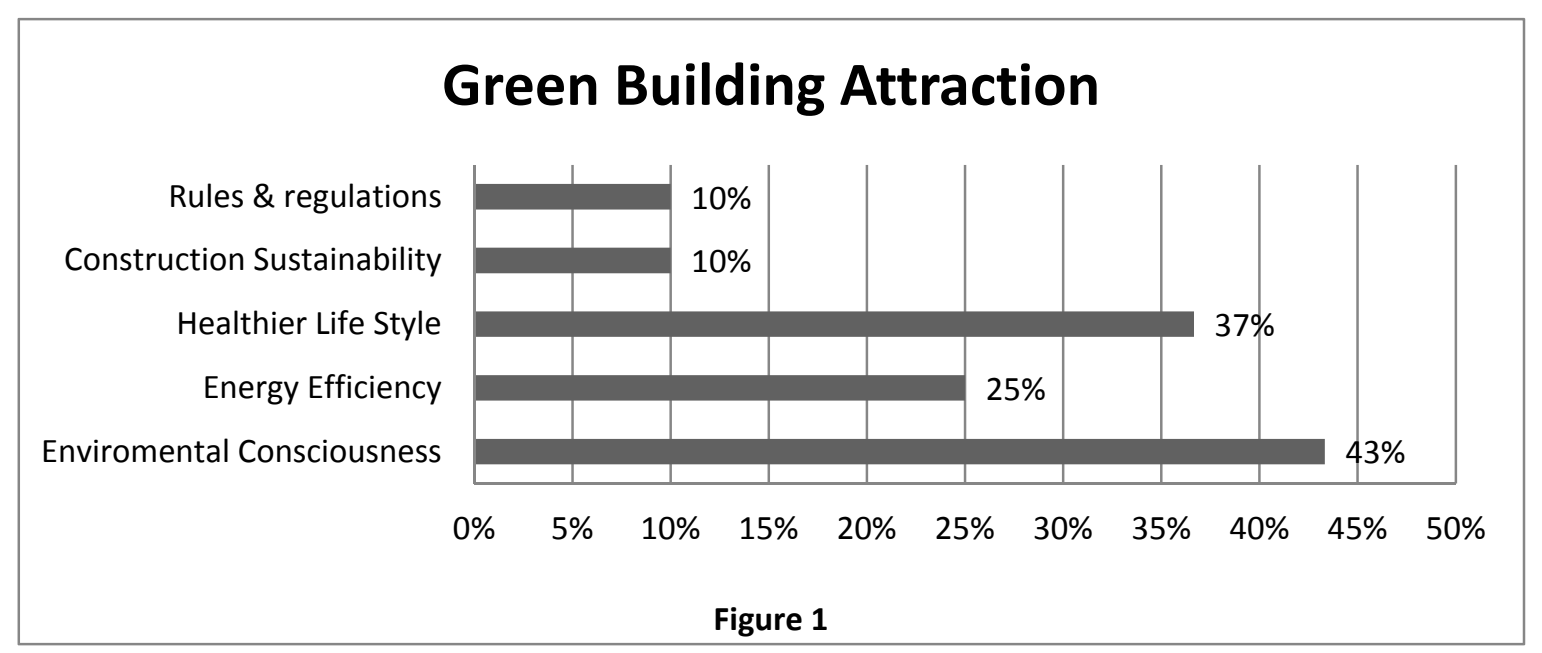

The second highest scoring factor is "healthier life style". This result reflects the importance of consumer traditional buying mood where selecting healthier flats coincides with the general trend of increasing health consciousness in the public eyes (Septic, Kozak and Cohen, 2005, p.22). Environmental consciousness cultivated the highest number of participant opinions with $43 \%$; it is important to realize that the public may show higher level of consciousness about the environment, but act differently at the time of purchasing (Schnitzer, 2010, p. 37). Efficient use of energy and resources scored significantly with $25 \%$; as expected, specific features of Green Buildings score substantially higher than general terms. On the down side, construction sustainability and obligatory rules scored poorly with $10 \%$ each; the observation is that the general public acts negatively toward green obligatory regulations (Moisander, Markkula and Eraranta, 2010, p.75). It enhances the study's view that the key toward Green Building development comes from consumer selection, not through rules and regulations. Construction sustainability, in the author's view, is a complicated terminology to the regular participant. The low score might have come from the lack of understanding of the term or it could have also come from the detachment of the individual buyer from the scientific proposed benefits.

The second question of the first group asks about the reason one might buy or rent a Green flat. The scores of each feature are shown clearly in Figure 2. 


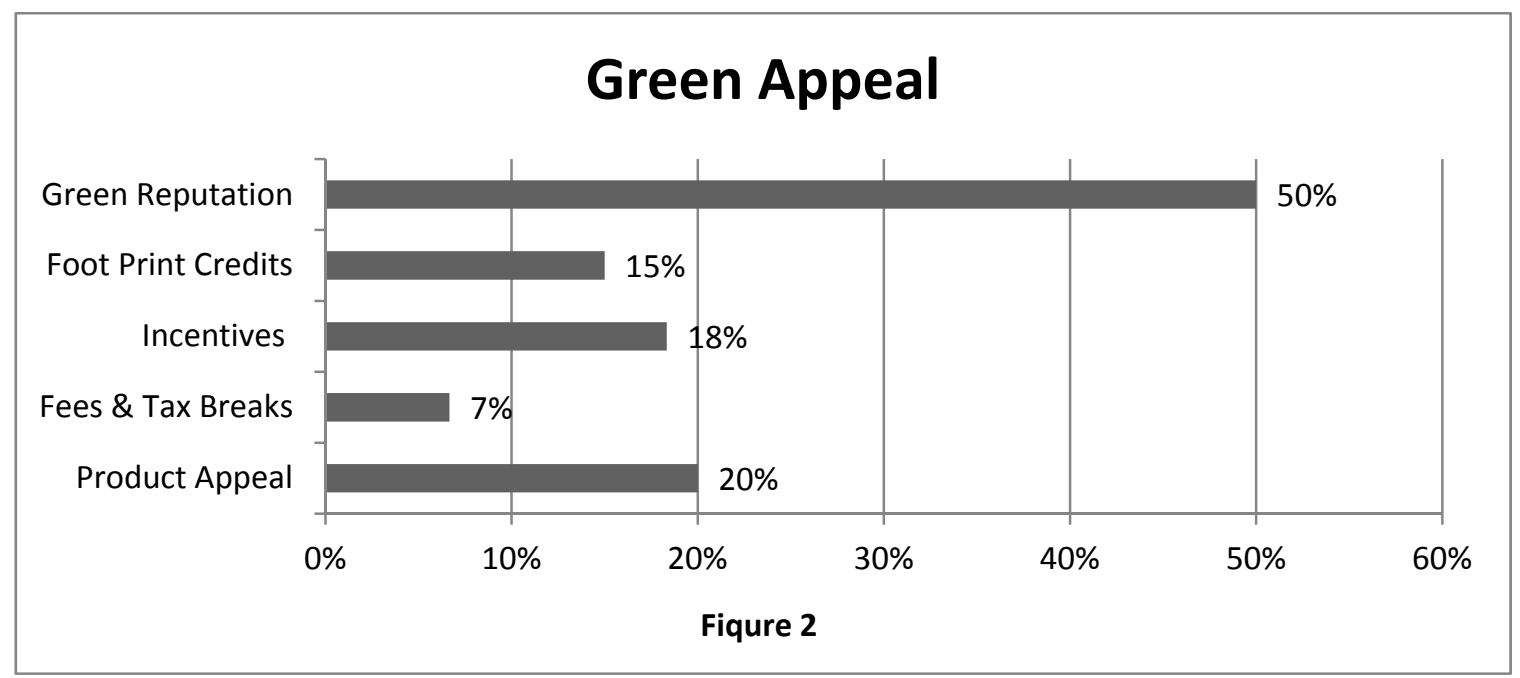

Green reputation cultivated more than $50 \%$ of the answers, which indicates the significance of two main implications. The first one is that regular consumers perceive green products very well where the second observation is the fact that "Green reputation" is a good initial marketing tool.

The next question was designed to ask about participants' favorite aspects. The two highest scoring aspects are indoor environment and transaction price. According to USGC (2008, p. vii), indoor environment includes air quality, smoke control, ventilation, site air quality, low emitting materials, lighting, thermal comfort and daylight. This fact provides developer with one useful piece of information which is that concerned parties have to work on improving all of their indoor environment subordinate elements.

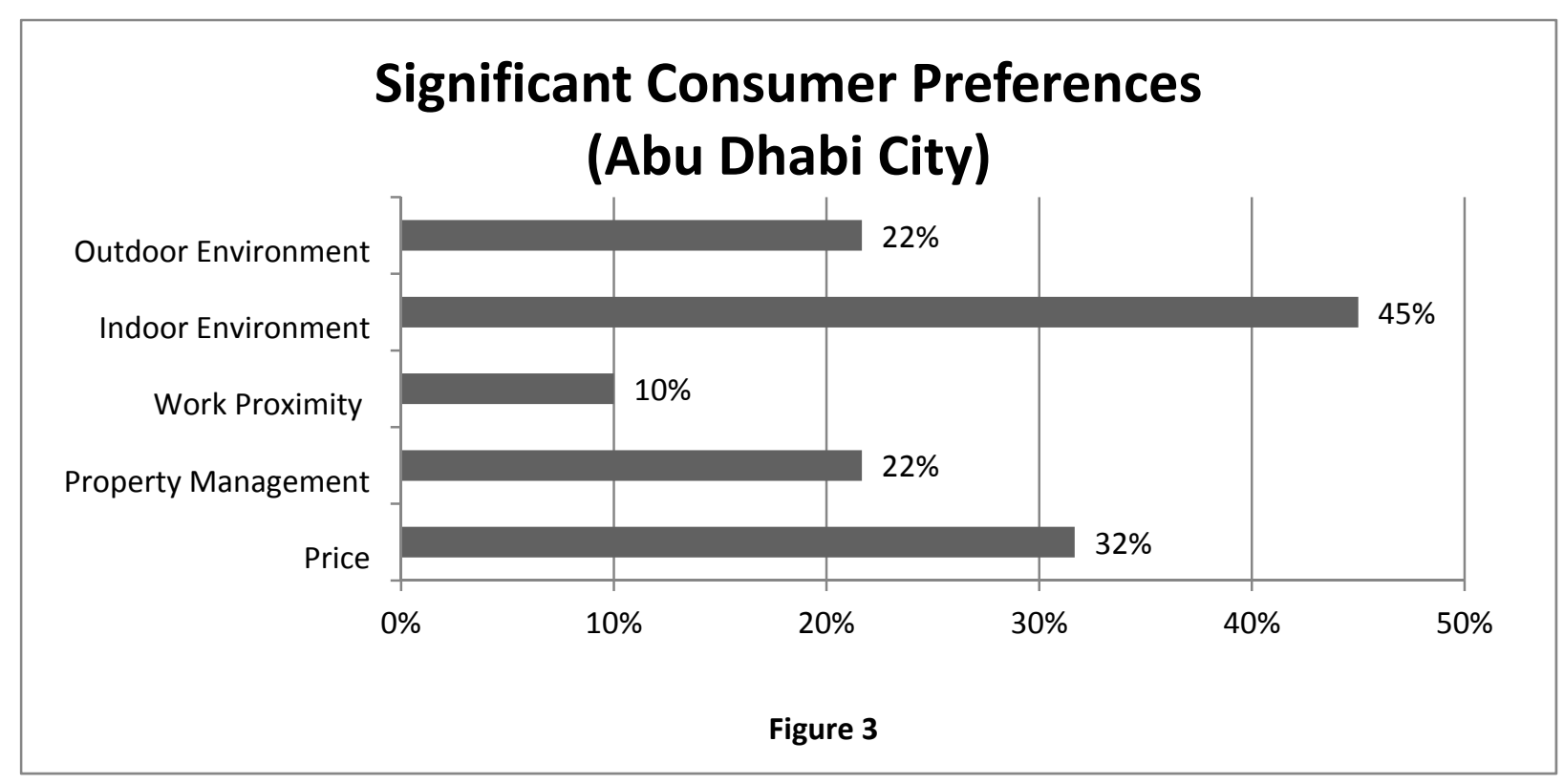

Price, as expected, is always an important element in any decision the consumer might take (Figure 3). Despite the fact that the other three elements scored less, the recorded percentages are significant enough to consider when selling Green properties. These results are qualified to be a base to future consumer preference studies on Abu Dhabi residents. 


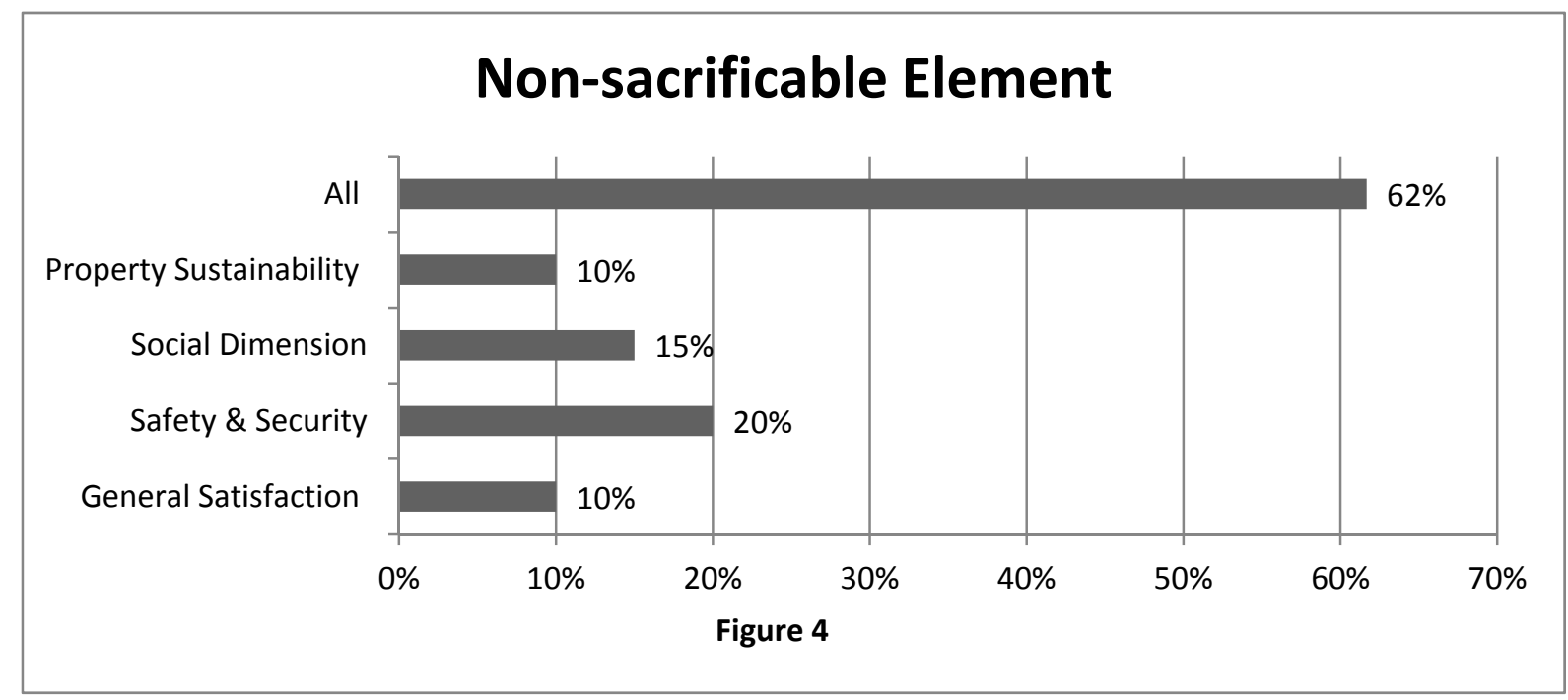

Question 4 looks into the issue from the opposite end; participants were asked about features they are not willing to compromise when buying a new Green home. The most significant answer was "none of the above" where "safety and security" scored $20 \%$ of the opinions. Close to two thirds of the participants refused to compromise any of the four elements listed in the question; this means that project managers should consider all of the four elements as essential features in any Green project. Compromising safety and security by a portion of the participants is attributed to two main reasons; the first one is the fact that the city has very low crime rate comparing to cities located in the Middle East. The second point is the confidence in the authority's ability to provide safe and secure environment to their citizens and expats. Participants think that the local authority is replacing the role of the developer in this specific point which is contradictory to Chinese consumer preferences (Jim and Chen, 2007, p. 429).

Question 5 is comprised of five items related questions based on the five main sections of USGBC (2008). To be able to evaluate the "green" building in depth, the question asks whether they expect the listed elements essential as Green Building features in their future property.

\section{Green Building Essential Elements}

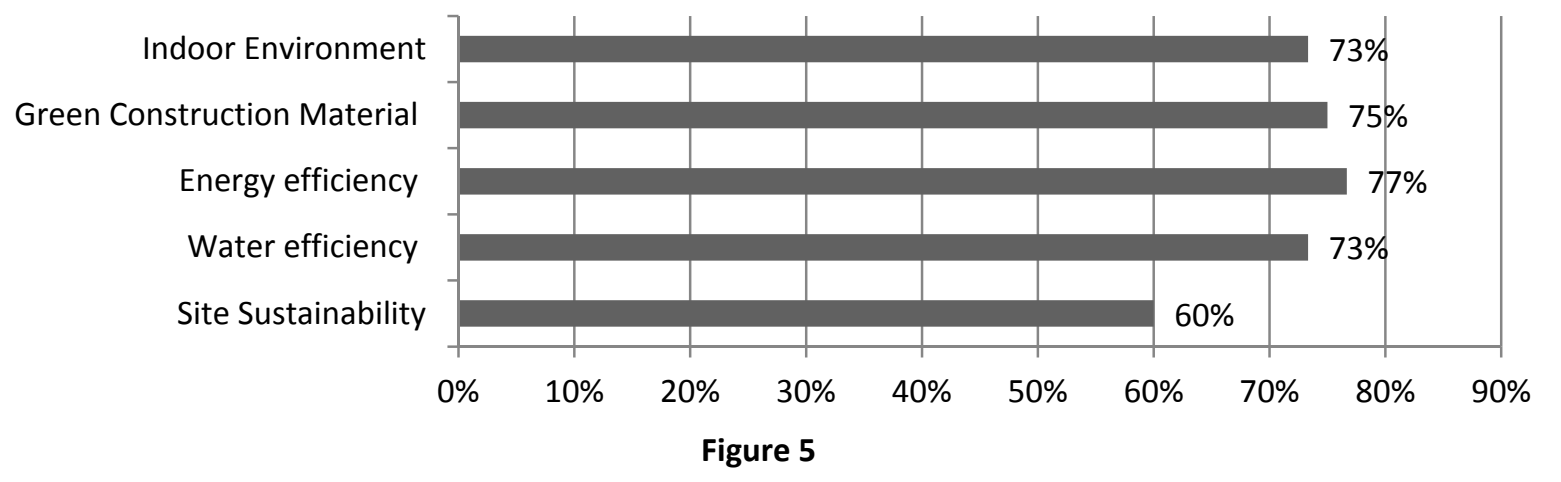

The results of all five answers were close and high at the same time (Figure 5). Four out of five answers scored more than 70 percent. Contrary to previous questions, the answer with the lower percentage is worth discussing; for example, site sustainability proves again to be a point of confusion. The score leads to two possible explanations; the 
first one is that most residents do not understand the term of "site sustainability." Second, site sustainability does not influence directly the life of tenants and property buyers which means that the consumer would be less interested in acquiring this feature. In short, the issue may capture the attention of participants who are concerned about the environment more than any other factor.

The last question in this group of questions links the economical element to consumer preferences. Participants were asked if they thought Green Buildings are positively correlated with economic growth or not. The answers did not indicate one direction over the other and more participant thought that economic growth and Green Buildings are positively correlated. Nevertheless, the percentage of people who disagreed is significant, shown in Figure 6 . The slightly higher positive responses provide two deep insights.

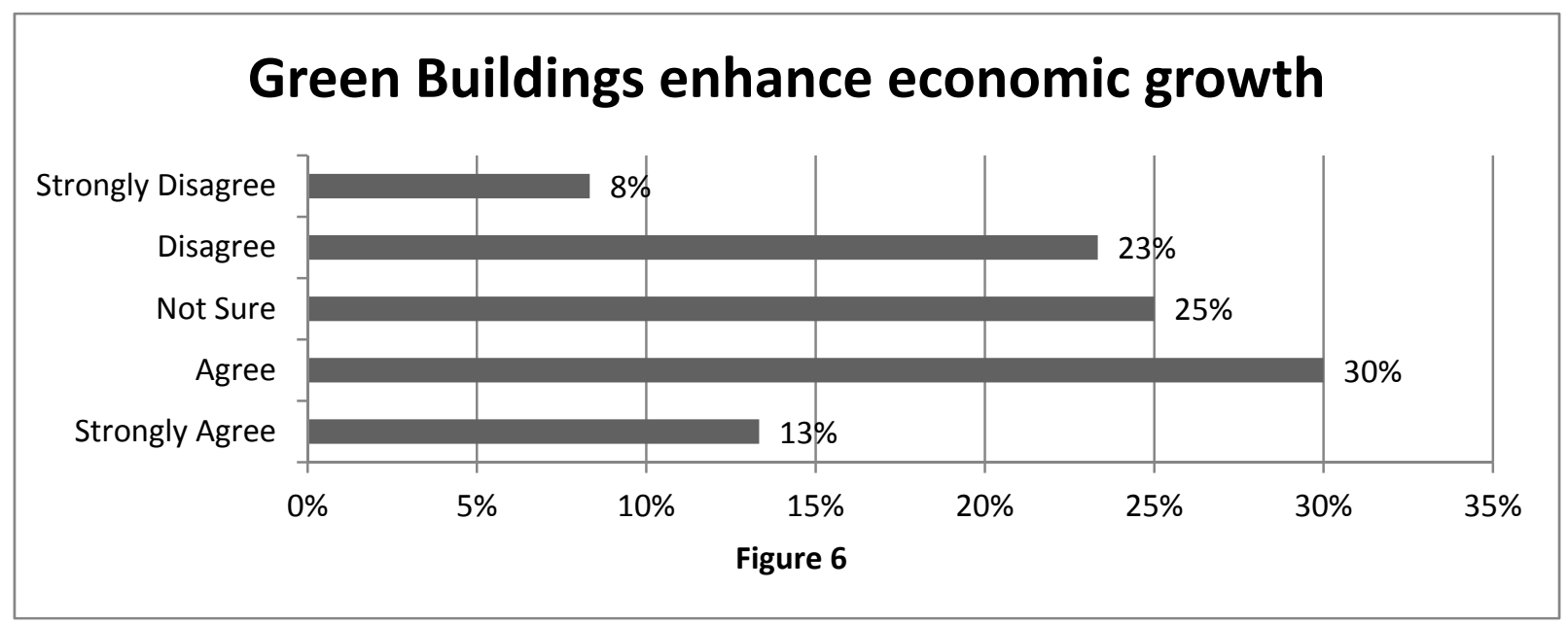

First, the results indicate that "Green" labels are positively perceived by the public. The second point is that maintaining public trust would be achieved only by further incentives and solid Green Building improvements.

The common objective of the above questions is to establish a number of consumer preferences about future Green Building properties. Certainly, buying goods by consumers is the real driving wheel of the industry (Moisander, Markkula and Eraranta, 2010, p. 77). First, as mentioned in the literature review, listing details and specific facts about Green Buildings is vital in gaining public positive reception. It is evident that elements such as efficient energy, healthier life style and indoor environment quality appeal more to consumers. In short, general environmental jargons are confusing and perceived much less positively; on the other hand, results indicate that environmental products, in general, and Green Buildings specifically are received well by the residents of the city of Abu-Dhabi. The findings of this set of questionnaire incorporated the idea of Septic, Kozak and Cohen (2005), who suggested that healthy home is growing concept for consumers. Finally, appealing features such as indoor environment have to be incorporated in future Green Building designs extensively. The purpose is to capitalize on consumer preferences commercially; consequently, Green Buildings would be able to attract more investments and larger market shares. In general, site survey findings are in line with literature review in chapter two

\subsection{Marketing Green Buildings}

The next group of questions is focused on consumer impression about Green Building marketing. To assess Green Building publicity, Question 7 asked if Green Buildings are publicized well in the city of Abu Dhabi. 


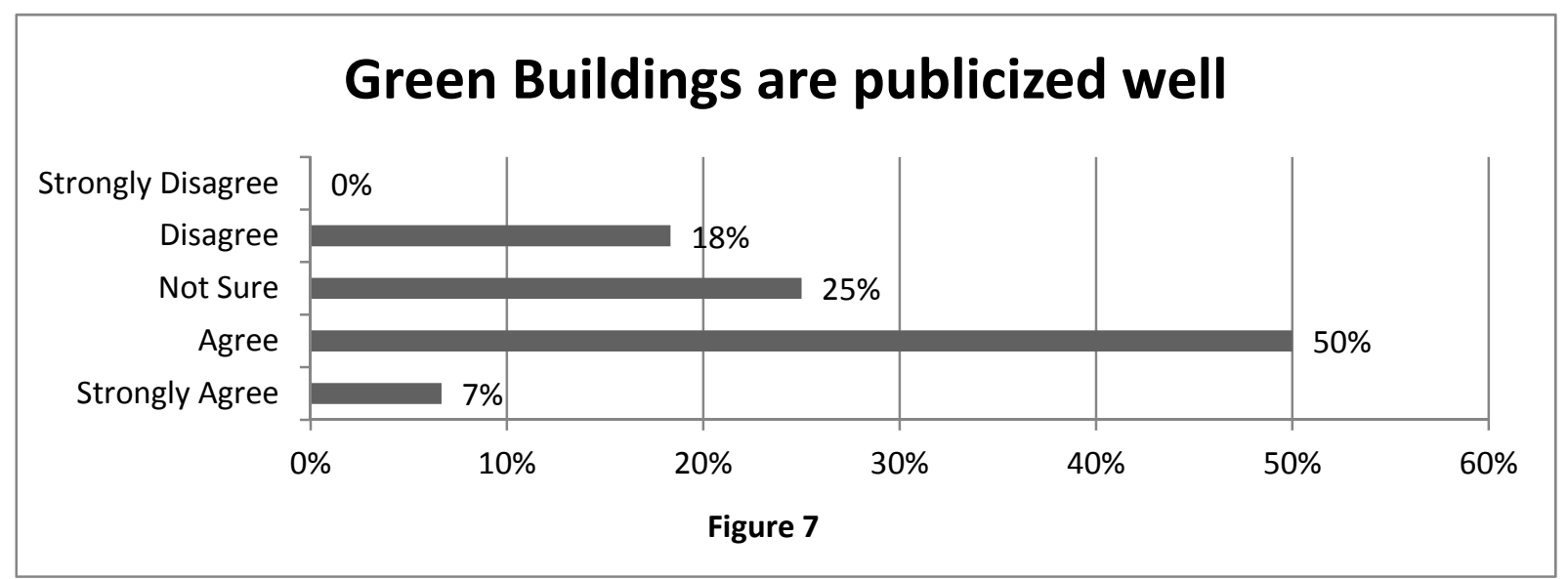

Figure 7 provides the results obtained from the preliminary responses of the participants; $50 \%$ of the participants think that Green Buildings are publicized well in the city of Abu Dhabi where only $18 \%$ of the participants were convinced that Green Buildings are not advertised well enough. The above results could be attributed to two main reasons; first, most residents in the city of Abu Dhabi are confusing Green Buildings with MASDAR projects. MASDAR is a semi-government company which is specialized in clean energy generation; these projects are not necessarily building projects. Therefore, media advertisements of the company are misleading in this context. The second reason is related to the general term of the question where subsequent questions provide contradictory results.

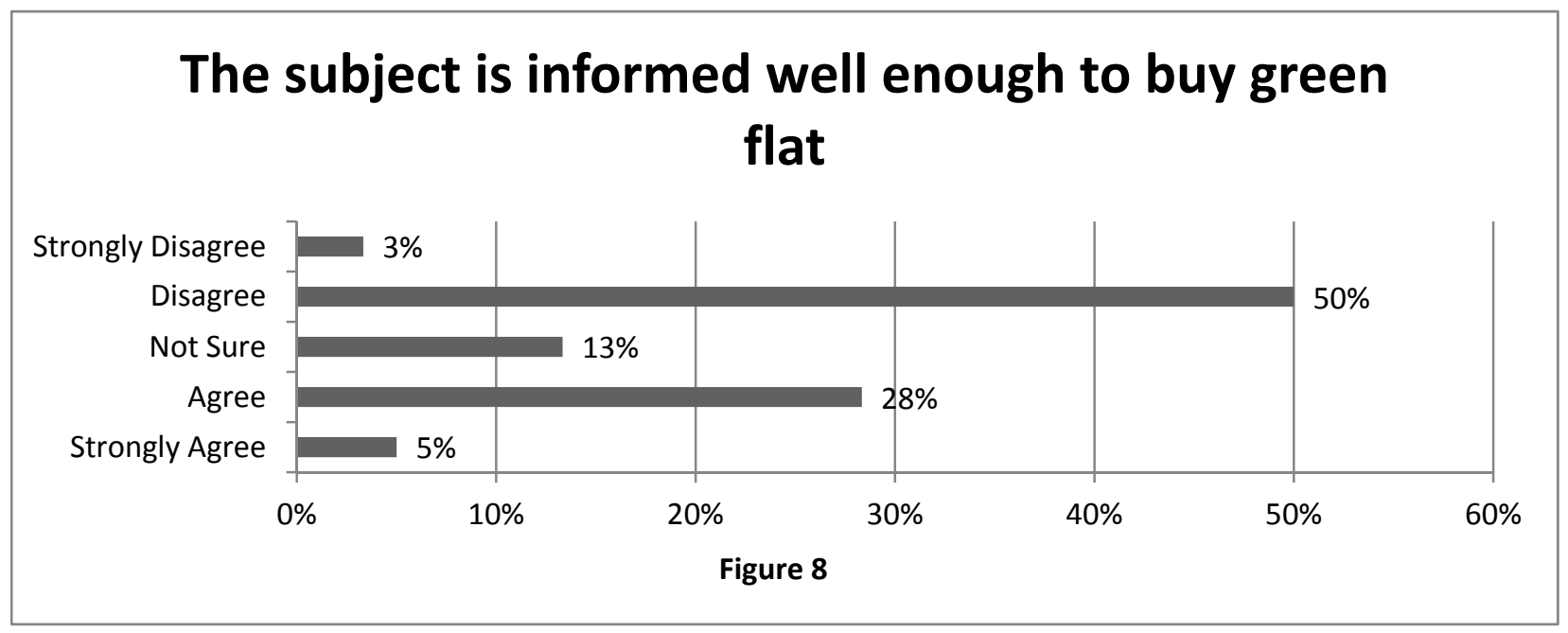

Figure 8 illustrates how results change when the question becomes more personalized. Question 8 asks the participants if they have enough information about Green Buildings to purchase a Green flat; as shown, 53\% of the surveyed participants thought they did not have enough information to purchase. Only one third of the participants thought they had sufficient information. When comparing Figure 7 to 8 , one realizes that there is a drop of $24 \%$ in the participants' confidence in their Green Building knowledge. As argued previously, personalizing environmental issues may lead to contradictory results.

The results confirm the findings of the previous one; participants were asked about their preferred marketing tool when buying their future Green flat. The results show that $38 \%$ of the participants preferred face to face meeting where the second highest scoring tool was web site information with $(27 \%)$. It is apparent from Figure 9 that 
participants would prefer an extensive informative marketing method when buying a new flat. What is interesting in these results is that acquiring huge amount of information indicates low confidence in their existing knowledge.

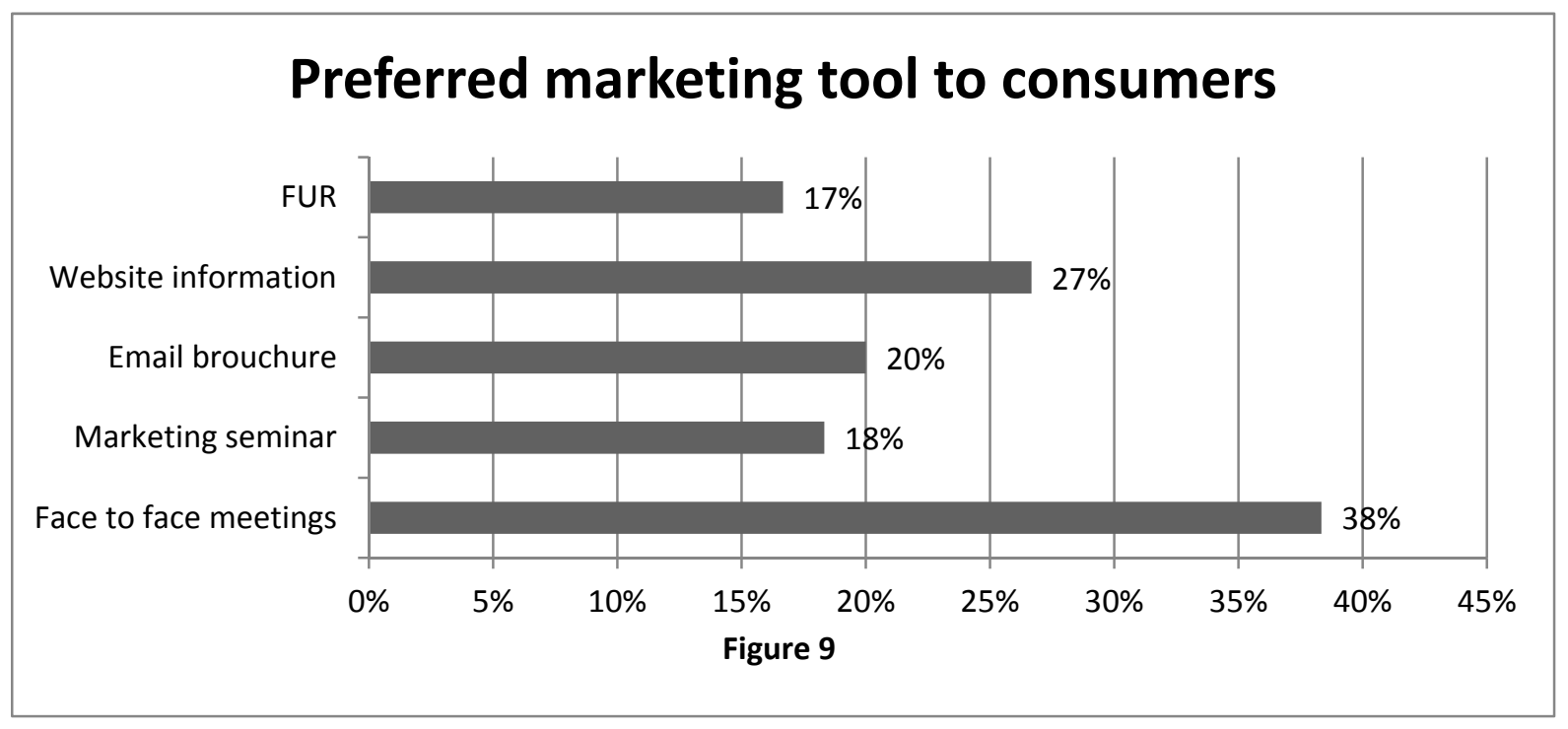

The lesson is not to trust general consumer knowledge about green facts; extensive information and education are essential to convince consumers to buy Green properties. This field needs more effort from concerned parties to provide higher public awareness about Green Buildings (Akehurst, Afonso and Goncalves, 2012, p.985).

The common objective of this group of questions was to evaluate consumer awareness level about Green Buildings, where a number of unanticipated results were extracted. The first un-anticipated finding was that consumer's knowledge about Green Buildings in the city of Abu Dhabi is not deep enough; it is apparent from the study that extensive education programs are needed for the public. As the questions became more specific, participants' replies indicated less certainties and much more hesitation. The second un-anticipated finding was that participants claimed firm environmental knowledge generally, but deeper discussions and questions indicated great thirst to credible information. These findings further support the concept of verifying existing information and plan for extensive informative means. Finally, concerned marketing stakeholders should stay away from general environmental jargons and provide specific scientific facts when approach consumers. Unlike the first group of questions, the findings were neither anticipated nor documented by literature review.

An interesting outcome of this study was proving that green properties could be sold on the base of green reputation but care has to be taken here, in line with the findings of Pilcher (2013) mentioned earlier. When residents look for green reputation, Green Buildings rise as the only option to satisfy this specific desire. Green reputation is, therefore, a powerful marketing tool for Green buildings; an exclusive feature which is not applicable to conventional buildings and traditional real estate developers. In addition, green reputations, as illustrated in Figure 10, appeals much more to younger generations as the old segment of the society. 


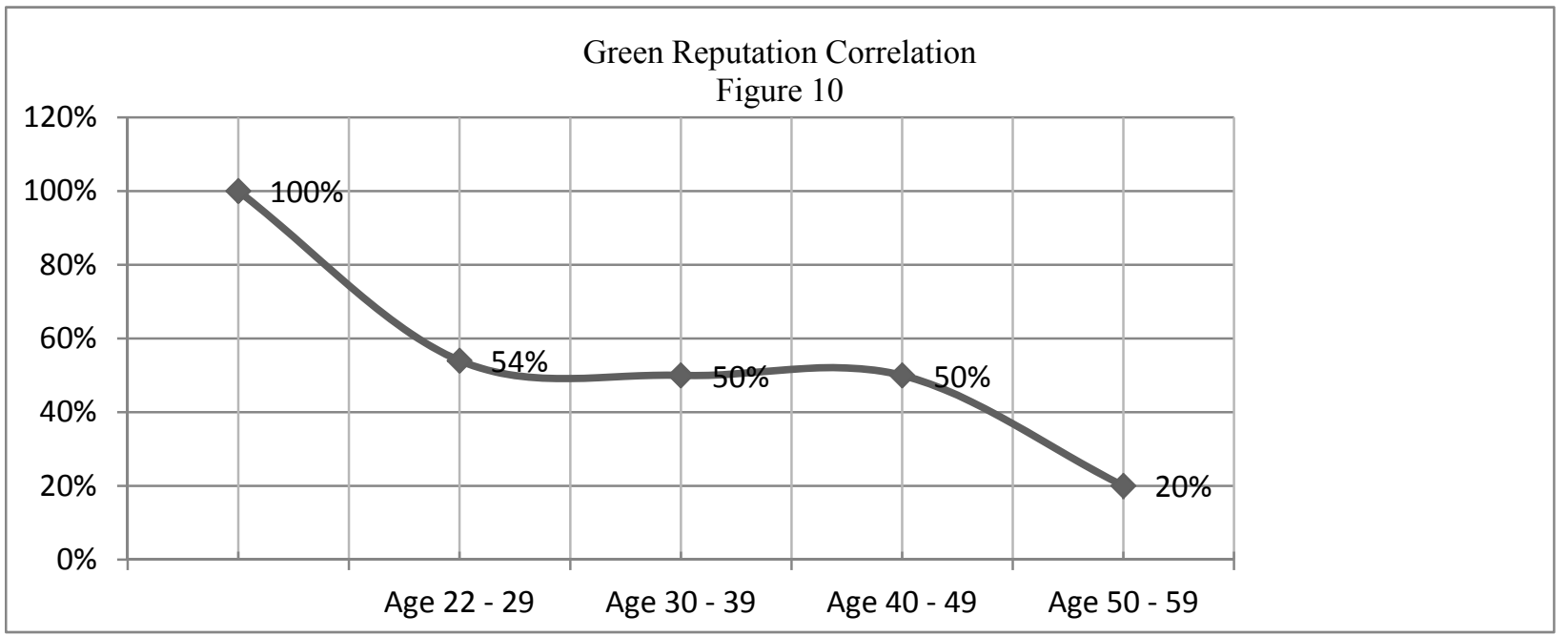

To summarize, all age correlations play a central role in any marketing campaign or any Green Building marketing strategy; therefore, promoting Green Buildings could only be done effectively through utilizing such correlation, which is in-line with the research main hypothesis.

\subsection{Findings Summary}

This study has shown that Green Buildings are marketable products with their own marketable features; marketing tools sometimes are different from the tools used to market conventional buildings. Just like any new and constantly changing industry, there are substantial number of challenges and problems which will only be solved by evaluating consumer preferences and how far the public is willing to bear for the sake of better construction practices (Kats 2003). Collecting views from Abu Dhabi local market contributed in drawing better picture about the local market, in addition to a number of specific and precise findings. First, the concept of building healthy homes played a central role in conventional buildings and still an appealing feature in Green Buildings. When it comes to constructing buildings, one has to think globally but act locally; Abu Dhabi residents dismissed highly valued features in other parts of the world such as security and safety but were keen to sophisticated green terms such as green construction sustainability. The lesson learned is that consumer preferences are affected directly with direct surrounding circumstances.

\section{Research Implications}

The results of this study indicate that marketing Green Buildings is more effective when specific features are listed; efficient energy, indoor environmental quality, air quality and fresh air are just few examples of specific features that attract consumers to Green Buildings. The findings of this study suggest that local residents require more education about Green Building materials and applications. The idea of constructing green buildings is still new and vague idea to substantial number of the participants.

Taken together, these findings suggest a number of correlations:

a- Green reputation is more effective marketing tool to younger residents than older ones.

b- The significance of transaction price of Green Buildings correlates negatively with age

c- Indoor environment quality correlates positively with residents' age

d- Water efficiency is less significant to older residents

e- Younger generation is more skeptical about Green building economic implications than older generation

Such appeal serves the environment substantially and effectively because sustainable life style would be an integral part of the public life. Also, competition and confronting challenges have greater chance to succeed than swimming against the current of market norms.

As a result, this work contributes to existing knowledge of Green Buildings by providing marketable green products with innovative marketing tools. This study is among the first ones reporting a common interest between consumers 
and sponsors on the local level. The preferences of Abu Dhabi consumers are identified, therefore, assist in understanding the role Green Building unique features that may beat conventional building features under certain circumstances. Current findings add substantially to a growing body of literature on providing new marketing model which may have more risks and challenges, but offer greater opportunities and better sales margins. This green product is not marketed on transaction price; in fact, the new sector is based on combining science and business in compatible wrap. In short, greater investments may flow into the green sector if the new marketing model is able to find wide range of consumers; such investment will promote Green Buildings in the city of Abu Dhabi and help the industry to flourish greatly in the future.

\subsection{Limitations of Current Study}

One of the main limitations of this study is that the survey does not cover periodical public opinions; the new industry of Green Buildings is developing every day which means that residents would change their positions toward some green issues accordingly. The public consciousness about the environment is increasing every day; it does not necessarily change the buying habits of the public dramatically but it will lead to more pro-green decisions. It is also expected that every year passes would add to the history track of the industry; consequently, more confidence in the technology will lead to favorable green buying habits.

The current research was not specifically designed to evaluate factors related to participant's individual green knowledge. The conducted interviews gave a sense that some participants did not have enough knowledge to answer some questions confidently. Working with the public based on their level of knowledge may lead to better understanding about consumer behavior toward Green Buildings. Thirdly, the study did not evaluate the culture impact on consumer purchasing habits; preferences collected proved that Chinese culture differs from preferences recorded in the city of Abu Dhabi. A related element is the psychological element of each consumer which contributes in taking one buying decision over another.

From stakeholder's perspective, the study did not cover the interest of each stakeholder separately; the appeal of Green Buildings was discussed in general, without highlighting elements in categorized manner according to the interest of each stakeholder. There is no doubt that contractors' interest varies greatly from the interest of developers, consultants, environmental agencies, or even government bodies.

\subsection{Recommendation for Further Work}

Residents of the city of Abu Dhabi are extremely diversified. Further work will be fruitful if future studies analyze the preferences of each segment of the society separately. A suggested segregation line would be UAE natives, Arab population other than Gulf citizens, Asians and Europeans. Other segregation social lines might be viable; the purpose is to provide better marketing approaches to stakeholders according to residents' background.

Further work might explore the contract type of the marketed property. It is assumed that the choice of property renting or purchasing may influence participant's feature preferences. Therefore, more work needs to be done to evaluate how preferences may differ according to contract type. Expanding the research from studying consumer preferences of individuals to analyzing the preferences of certain groups or bodies of the city may prove to be significant to the society. Also, it would be interesting to compare experiences of individual consumers to the experience of corporate as a whole. Conducting surveys and studies on group sponsors such as Public Work Department, Abu Dhabi Water and Electricity Authority, Abu Dhabi Environmental Agency and so on would produce new findings to concur uncharted territories.

\section{Conclusion}

This paper has argued that perusing consumer's preferences is the best instrument to advance and support the growth of Green Buildings. Due to the severe impact of construction on the environment, e.g. construction accounts for $40 \%$ of solid landfill waste in Europe (Rehm and Ade, 2013, p. 199), Green Buildings prove to be the most effective approach to respond to the pressing environmental issues and long term sustainability problems. The marketing strategy of Green Buildings is not identical to the one used for conventional buildings, especially that the industry of Green Buildings is new and evolving every day. The industry has its own share of obstacles and challenges. The additional risks associated with the nature of green construction demand additional appropriate measures to reduce their implications and service disturbance occurrences; consequently, marketing green construction will be much more practical and efficient. The key to success is to have Green Building expansion driven by consumer demand rather than enforced rules and regulations. 


\section{References}

Akehurst, G., Afonso, C., \& Gonçalves, H. (2012). Re-examining green purchase behaviour and the green consumer profile: new evidences. Management Decision, 50(5), 972-988, http://dx.doi.org/10.1108/00251741211227726

Brasington, D., \& Hite, D. (2005). Demand for Environmental Quality: A Spatial Hedonic Analysis. Regional Science and Urban Economics, 35(1), 57-82

Brohmann, B., Clamor, T., Heinzle, S., Rennings, K., Schleich, J., \& Wüstenhagen, R. (2013). Introduction and theoretical framework. Sustainable energy consumption in residential buildings, pp. 3-37.

Easterby-Smith, M., Thorpe, R., \& Jackson, P. (2008). Management research (4th ed.). London: SAGE Publications.

Gauthier, J., \& Wooldridge, B. (2012). Influences on sustainable innovation adoption: Evidence from leadership in energy and environmental design. Business Strategy and the Environment, 21(2), 98-110

Haddock-Fraser, J.E., \& Tourelle, M. (2010). Corporate motivations for environmental sustainable development: Exploring the role of consumers in stakeholder engagement. Business Strategy and the Environment, 19(8), 527-542.

Jim, C., \& Chen, W. (2007). Consumption preferences and environmental externalities: A hedonic analysis of the housing market in Guangzhou. Geoforum, 38(2), 414-431.

Kats, G. (2003). The Costs and Financial Benefits of Green Buildings. Sacramento, CA: California Sustainable Building Task Force.

Levin, E.R. (2013). Building Communities: The Importance of Affordable Green Housing. National Civic Review, $102(2), 36-40$.

Liu, Y., \& Wang, X. (2013). Selection of GBSC Management Strategies Based on Government Subsidies and Consumers' Environmental Preferences. International Journal of Applied Environmental Sciences, 8(20), 2577-2590.

Moisander, J., Markkula, A., \& Eräranta, K. (2010). Construction of consumer choice in the market: challenges for environmental policy. International Journal of Consumer Studies, 34(1), 73-79. http://dx.doi.org/10.1111/j.1470-6431.2009.00821.x

Pilcher, G.R. (2013). The True Meaning of Green. Adhesives \& Sealants Industry, 20(5), 10. Business Source Complete, EBSCOhost, viewed 19 April 2015.

Rehm, M., \& Ade, R. (2013). Construction costs comparison between 'green' and conventional office buildings. Building Research \& Information, 41(2), 198-208.

Schnitzer, E. (2010). Marketing to the Green Consumer. Multi-Housing News, 45(7), 36-37.

Sharples, S., \& Radhi, H. (2013). Assessing the technical and economic performance of building integrated photovoltaics and their value to the GCC society. Renewable Energy, 55, 150-159.

Shiha, A., Gupta, R., \& Kutnar, A. (2012). Sustainable Development and Green Buildings. Wood Industry / Drvna Industrija, 64(1), 45-53. http://dx.doi.org/10.5552/drind.2013.1205

Snyder, P., Tate, P., \& Winters, L. (2011). How Boomers Can Help the Nation Go Green - Emerging Encore Career Opportunities in the Green Economy. Catalyst (21519390), 40(2), 11-19. Education Research Complete.

Spetic, W., Kozak, R., \& Cohen, D. (2005). Willingness to pay and preferences for healthy home attributes in Canada. Forest Products Journal, 55(10), 19-24.

Thatcher, A., \& Milner, K. (2012). The impact of a 'green' building on employees' physical and psychological wellbeing. Work, 41, 3816-3823.

Yudelson, J. (2007). Marketing Green Buildings. Heating/Piping/Air Conditioning Engineering, May, Academic Search Complete, EBSCOhost. Retrieved September 5, 2013, from http://ehis.ebscohost.com.ezproxy.liv.ac.uk/eds/pdfviewer/pdfviewer?sid=afbb3e38-d432-4778-a2d3-e53aca0f8 $843 \% 40$ sessionmgr $113 \&$ vid $=9 \&$ hid $=5$ 